\title{
SENTINEL-1 INSAR PROCESSING OF CORNER REFLECTOR INFORMATION IN THE NORTHERN-BOHEMIAN COAL BASIN
}

\author{
I. Hlaváčová a , L. Halounová ${ }^{\mathrm{a}}$, P. Stanislav ${ }^{\mathrm{b}}$ \\ ${ }^{a}$ Czech Technical University, Faculty of Civil Engineering, Department of Geomatics, Prague, Czech Republic - (ivana.hlavacova, \\ lena.halounova)@fsv.cvut.cz \\ ${ }^{\text {b }}$ Severní, energetická, a.s., Most, Czech Republic - p. stanislav@sev-en.cz
}

Theme Session ThS3

KEY WORDS: Sentinel-1, corner reflector, InSAR, mining area, subsidence, landslides

\begin{abstract}
:
The mining area previously monitored by TerraSAR-X InSAR is now monitored by Sentinel-1 InSAR. Although the processing of the IWS (TOPS) mode requires additional processing steps and the coregistration has to be performed with the precision of 0.001 pixel (in the azimuth direction), if an area within one burst is processed, such a precise coregistration is not necessary.

Information from 11 corner reflectors is evaluated, and significant movements at one of them were detected. Although it seems to be uplift, it is more probable that the movement is in down-the-slope direction, which has a negative sensitivity with regard to the satellite line of sight. The movement is similar to the one detected by TerraSAR-X satellite in the past. At the end of the monitoring period, the movement seems to settle down; future monitoring will show more about the dynamicity of the movement.
\end{abstract}

\section{INTRODUCTION}

The area of Northern Bohemian has a coal bed. The coal has been mined since medieval times and the mining still continues, however the techniques and equipment change. During $20^{\text {th }}$ century, the countryside was heavily devastated when several large open mines arose, also with waste dumps nearby. Now, some of the open mines are still active, while the old (empty) ones are already reclaimed for various purposes: agriculture, free-time activities (racing circuit), forests or lakes. In addition, there are several older deep mines in the area, causing subsidence in some areas.

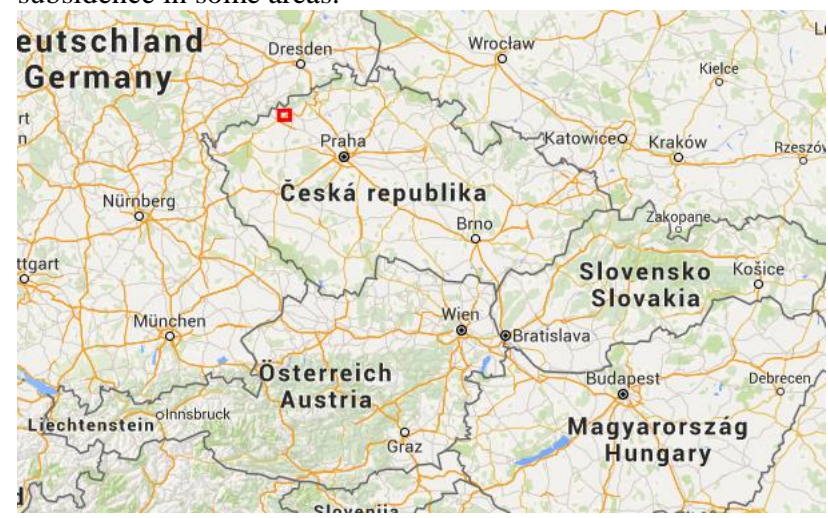

Figure 1. The area of interest (red rectangle).

Above the open pit mine, the Krušne Hory mountains rise up to 800 metres above the sea level. Surface mining of the thick brown-coal seam along the mountain range poses a great number of challenging aspects concerning the long-term stability of the mountain slopes. Therefore, these aspects have been thoroughly debated among experts since the time when the first mining plans were designed. As a result, the technical and mining plans had to incorporate various geodetic, geotechnical, geological, and other methods of monitoring of the stability of the Krušné Hory slopes. The slope stability monitoring systems that were used around the open pit mine mostly included a complex of single measuring points which covered only a limited area. The monitoring results were only of a local significance and did not cover the whole area of interest, including the open-pit mine as well as its surroundings. In 2005, an automatic measuring station was established to monitor the overlying sediments at the side slopes of the open-pit mine. The station is still in operation and has provided more complex and reliable results. Nevertheless, the implementation of the interferometric monitoring system has facilitated the monitoring of such a vast area independently of the ground measurements. In 2008, 11 corner reflectors were installed around one of the huge open mines, to monitor possible movements at selected sites, because the surroundings of the mines is mostly vegetated, causing low coherence in C-band. All the reflectors were installed in areas that were assumed stable. First InSARmonitoring attempts were performed using ENVISAT ASAR data (with lots of acquisition conflicts so that not enough images could be ordered before the satellite end of operation in 2010), then TerraSAR-X imagery was used between 2011-2014 (Hlaváčová, 2012, Halounová, 2013, Hlaváčová, 2014).

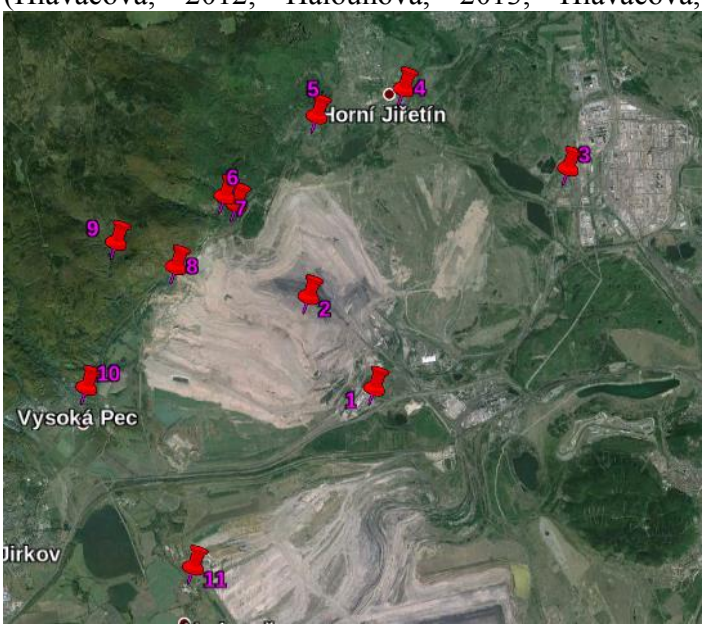

Figure 2. The position of the corner reflectors within the area of interest. 
Sentinel-1 imagery is available since October 2014. Data are provided for free to anybody and each scene covers a large area $(250 \times 250 \mathrm{~km})$. However, due to the requirements to cover as much area of the world as possible (in order to avoid potential acquisition conflicts from different users), TOPS mode is used for land acquisitions, with a reduced resolution of approximately $5 \mathrm{~m}$ in range by 20 meters in azimuth. In addition, the SLC images in the TOPS mode need an additional processing (deramping, reramping and coregistration with the precision of 0.001 pixel (Prats-Iraola, 2015)) which is not yet completely supported within common InSAR softwares.

Imprecise coregistration results in phase jumps in the interferograms (between individual bursts). Fortunately, our area of interest (AOI) is contained in one burst.

For Sentinel-1, it is advertised that perpendicular baselines are short (mostly shorter than $200 \mathrm{~m}$ ) and the acquisitions are performed for most of the satellite passes (each 12 days), so also temporal baselines are short and the number of images available is high enough even after 16 months of acquisitions.

30 scenes were processed (some scenes had to be excluded due to the azimuth image shift; processing of subsequent images is not yet implemented in the SarPROZC software), acquired between October 12th, 2014, and February 4th, 2016.

\section{METHODOLOGY}

The reflectors were oriented so that their axes coincide with the Sentinel-1 radar ray for descending pass of the satellite. For reflector orientation computation, the first acquired scene was used, so during the first acquisitions, the reflectors were still oriented to the TerraSAR-X satellite. By mistake, the reflectors are not trihedral, but dihedral, and therefore very sensitive to the orientation in the horizontal direction; fortunately, their reflectivity is high enough even in the first images and after the re-orientation (by 1-2 degrees in the horizontal direction and by 8 degrees in the vertical direction) their reflectivity improved only by about $20-30 \%$.

The perpendicular baselines of the Sentinel-1 satellite do not reach more than $100 \mathrm{~m}$ if the master image is well chosen and therefore the phase deviations resulting from an imprecise DEM are not significant. For our AOI, we use a high-resolution DEM created from aerial interferometry in 2013, however the terrain changes quickly in the mining area. In addition, levelled heights of the scatterers were manually imported to the DEM (unfortunately, the last levelling campaign ran in 2011, so the levelling results cannot be compared to InSAR results).

As the SarPROZC software does not implement phase and position interpolation for a point scatterer, standard (not interpolated) phase values were used. In order to improve the precision, it is advised to estimate the residual height even in the
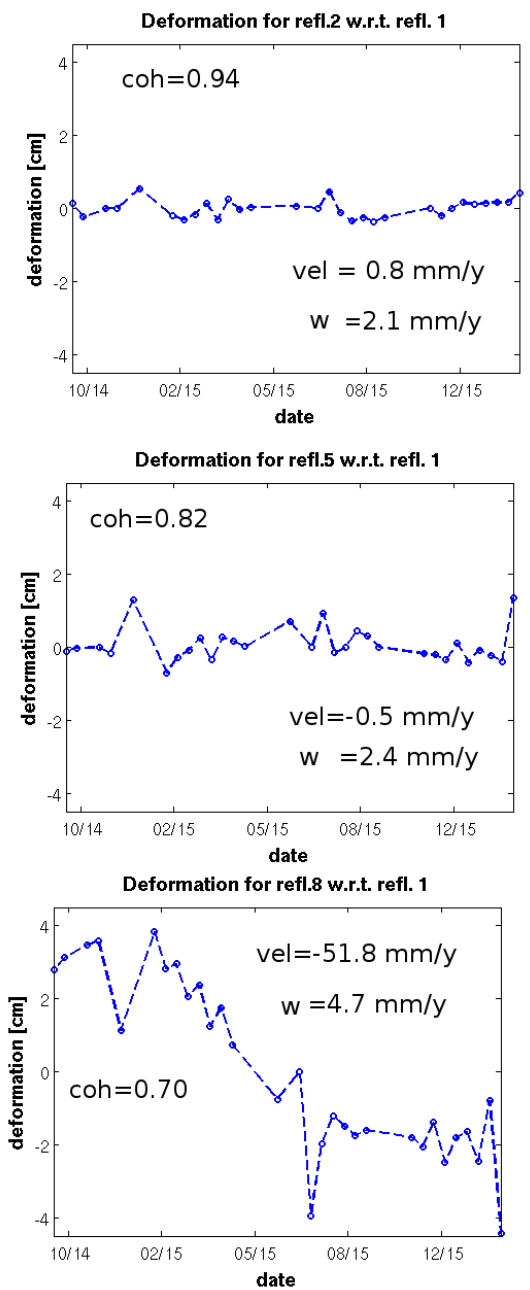

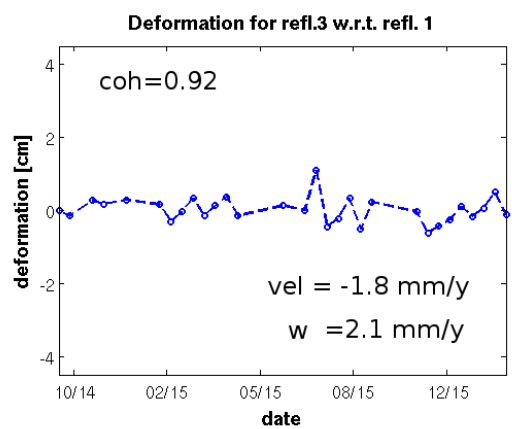

Deformation for refl.6 w.r.t. refl. 1

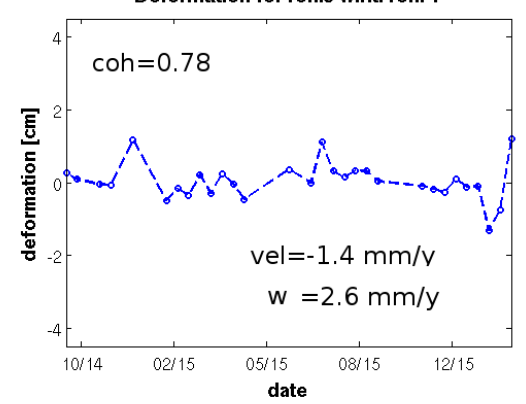

Deformation for refl.10 w.r.t. refl. 1

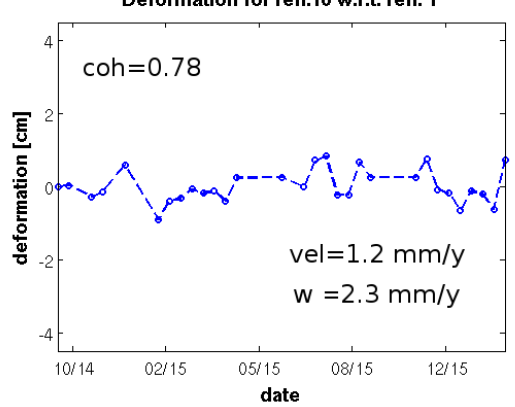

Deformation for refl. 4 w.r.t refl. 1

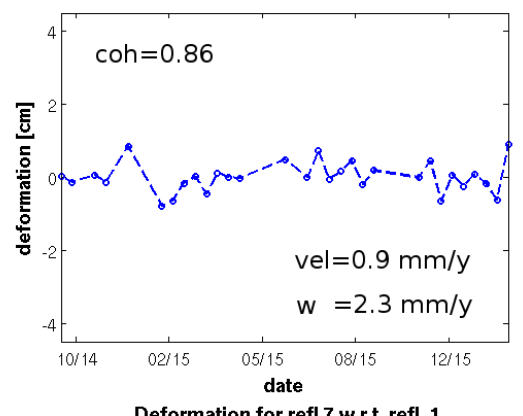

Deformation for refl.7 w.r.t. refl. 1

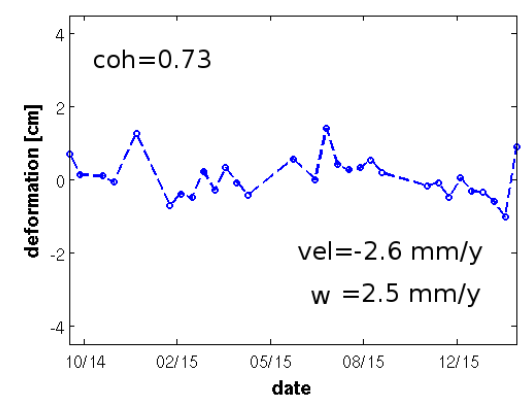

Deformation for refl.11 w.r.t. refl. 1

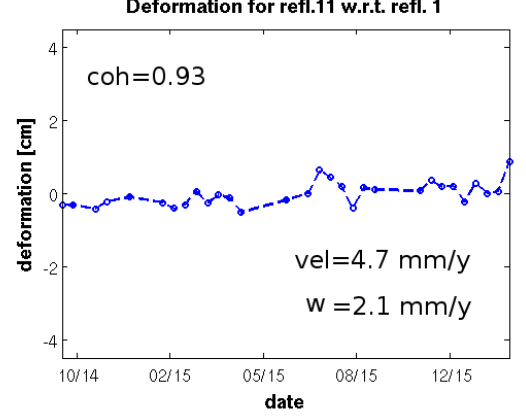

Figure 3. Sentinel-1 estimated movements for reflectors 2-8 and 10-11 with regard to reflector 1 [cm]. Reflector 9 is not imaged due to low reflectivity and a unrealistic height estimation. The movements are recalculated to the vertical direction with the assumption they are purely vertical for all reflectors except for reflector 8 , where the movement is recalculated to the down-theslope direction, in which the movements are expected. The $w$ parameter represents the accuracy of the velocity estimation

(periodogram width). 
case when the accurate (levelled) height is available as the height information is connected to the uncompensated slant range (Ketelaar, 2008) sub-pixel position. For all the reflectors, the estimated residual height was lower than $7 \mathrm{~m}$, in comparison to the $3 \mathrm{~m}$ range resolution (incidence angle is $39.6^{\circ}$ for the AOI) which means that the reflector center (taken as the pixel with highest reflectivity) is shifted with regard to the most reflective pixel, possibly for a little more than one pixel. For reflector no. 9, the estimated residual height is even over $26 \mathrm{~m}$ (in this case, we attribute the problem to the reflector orientation, deformation of the plates or debris inside as its reflectivity is also significantly lower in comparison to other reflectors). This reflector was excluded from processing due to it low coherence and irreliable results.

The individual processing of the reflectors (with no points selected except for the reflectors) was not successful due to long distances between the reflectors $(3-5 \mathrm{~km})$ resulting in incorrect ambiguity estimations.

Atmospheric delay was not estimated due to technical problems. One of the reflectors (no. 1) serves as the reference point for processing of the whole area.

Together with residual height and velocity estimations, the software SarPROZC outputs the width of the periodogram, to be used as the accuracy measure. It is not directly comparable to standard deviation, the values are significantly higher than the intuitively expected standard deviation values (e.g. the accuracy of the residual heights is $6-8 \mathrm{~m}$ for all the reflectors), but it may serve as an interval of possible values of the residual height/velocity and an intuitive measure of whether the estimated velocity is significant or not.

\section{RESULTS AND DISCUSSION}

Figure 1 depicts the detected movements for the reflectors, recalculated to the vertical direction with the assumption that the movements are purely vertical; except for reflector 8 . Phase/movement jumps are present for most reflectors for the date of December $23^{\text {rd }}, 2014$, which we attribute to an anomaly caused by e.g. atmospheric delay, and we do consider it an error.

At reflector no. 8, the LOS movement looks like an uplift (not imaged here). As this reflector is located right under the Krušné hory slope (however the slope at this point is only $3.8^{\circ}$ ) and frequent landslides happen at this slope, we consider that this point is moving in the direction of the slope. According to (Barboux, 2011), the sensitivity in the direction of the slope is

$s=\cos \theta \sin u+\sin \theta \cos u \cos (v-\alpha)$,

where $\theta$ is the incidence angle, $u$ is the local slope, $v$ is the local aspect (of the slope normal) and $\alpha$ is the azimuth of the radar ray; the sensitivity is then defined as
$d_{L O S}=s \cdot d_{R E A L}$

where $d_{L O S}$ is the measured deformation and $d_{R E A L}$ is the real

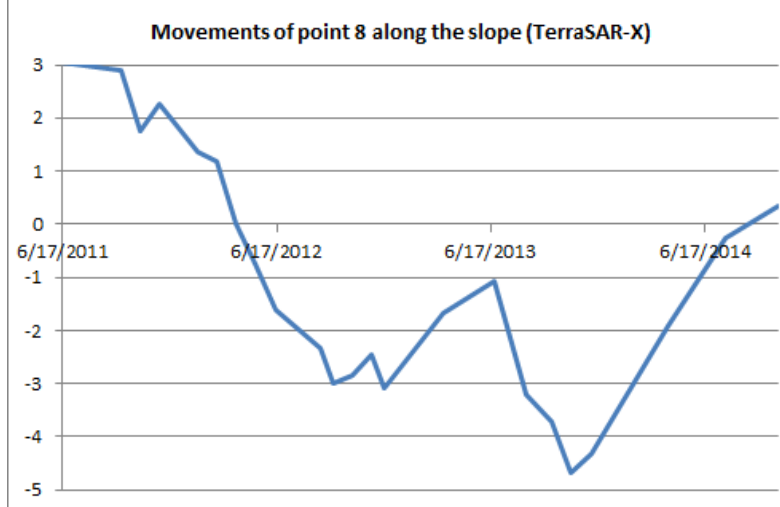

Figure 4. Estimated movements for reflector 8 measured by the TerraSAR-X satellite during 2011-2014, recalculated to the down-the-slope direction. The first half of the last "increase" is disputable because the difference between two subsequent images is close to half of the ambiguity, so it is possible that instead of the "uplift" here, it can be shifted 5 $\mathrm{cm}$ downward (however, some movement up remains).

deformation in a different direction, in this case in the downthe-slope direction.

For the area close to reflector 8 , the sensitivity is evaluated to be approx. -0.4 (within the close neighbourhood of the point, values change from -0.35 to -0.45 , satellite inc. angle is $39^{\circ}$ ) for the Sentinel-1 satellite, descending track 95). So, the measured "uplift" in the satellite line of sight (LOS) of $21 \mathrm{~mm} /$ year in average corresponds to the slide of approx. $5 \mathrm{~cm} /$ year in the direction of the slope. Processing only 13-month data, the movement velocity was estimated to approx.. $6 \mathrm{~cm} /$ year, and the slowing down is visible at the end of the time series in figure 1. For the previously used TerraSAR-X (see fig. 2) data, periods of "subsidence" and "uplift" take turns (the last uplift is disputable due to possible unwrapping error caused by a long period (almost 4 months) between subsequent acquisitions; however, even in such a case, the combination of both directions of the movement is still present). Satellite incidence angle is $31^{\circ}$, the sensitivity reaches values around -0.24 .

For the Sentinel-1 data, it seems that the "uplifts" can be attributed to errors (possibly atmospheric delay or even unwrapping errors of $27 \mathrm{~mm}$ ), and at the end of the monitoring period, the movement seems to settle down. 

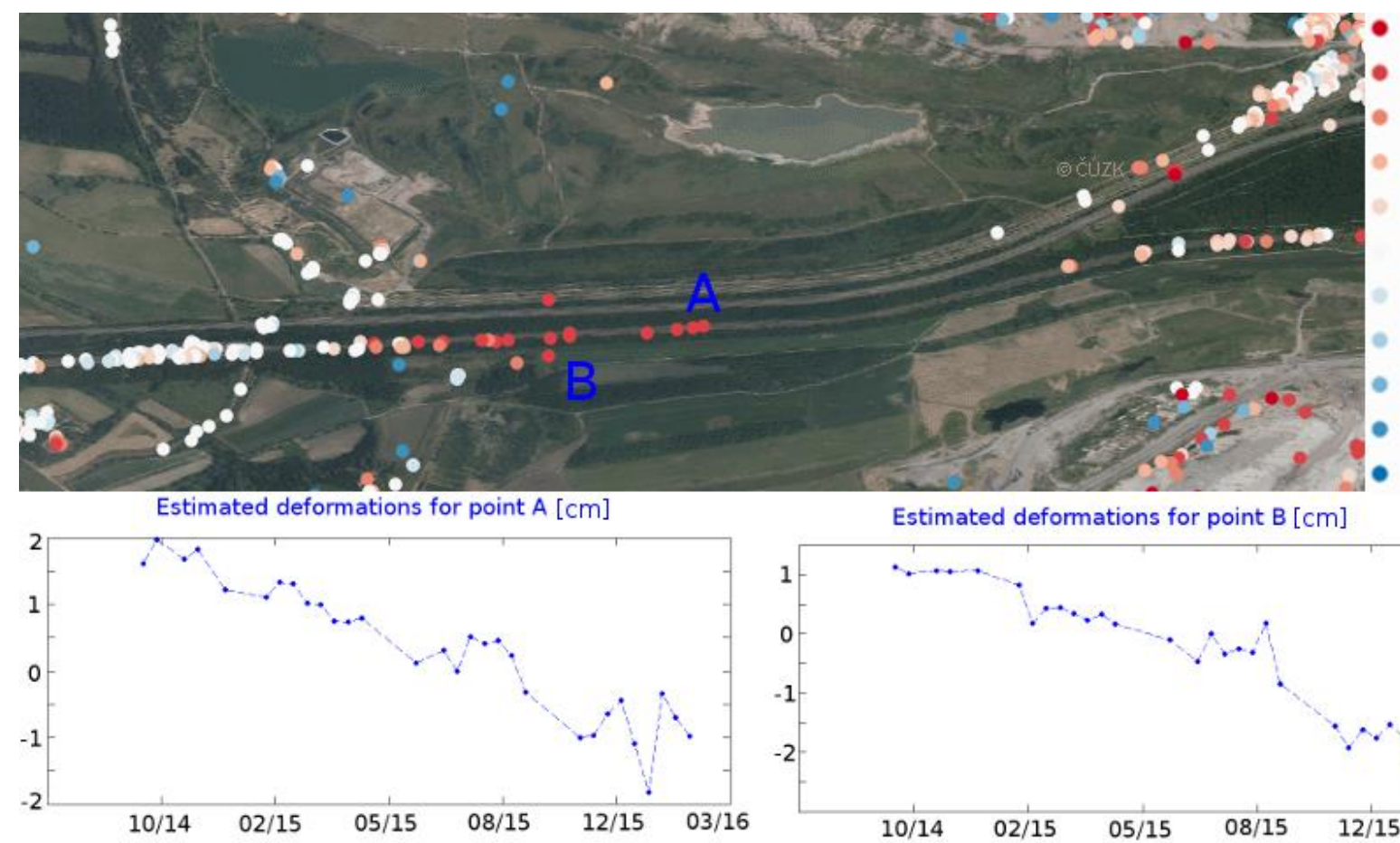

Estimated deformations for point $B[\mathrm{~cm}]$

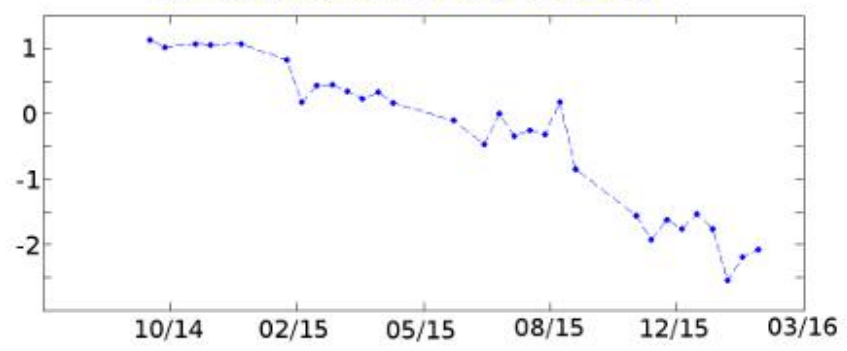

Figure 5. Sentinel-1 estimated movements (in LOS) for the famous Ervěnice corridor. It is evident that even after 30 years, it is still subsiding, however, the velocity (in the vertical direction) does not exceed $4 \mathrm{~cm} /$ year (the direction is assumed to be vertical, the sensitivity to vertical movements is 0.77 ). The movements are estimated with regard to reflector 1.

The movements of reflector 8 can be interrelated with recent earthworks below this reflector. Since 2010, vast earth-moving operations have been conducted in the north-western slopes of the open pit mine, which are situated right below the reflector. The operations were aimed at long-term stabilization of the slopes and they also might have modified the hydrogeological conditions of the area. As they were finished in 2015, the consolidation of the area will last for several next years. Thus, it can be interesting to follow the potential movements of this reflector in the near future.

The slow uplift, detected at reflector 11, was detected there also by levelling between 2008-2011. The estimated movements of other reflectors are smaller or comparable with the accuracy of the estimated velocity, and therefore are assumed to be stable.

Figures 5 and 6 display the estimated movement in the surrounding areas. Inside the mines, there are many points with higher coherence (only points with coherence above 0.7 are displayed) but their estimated movements seem unreliable, probably due to imprecise DEM, together with possible (significant) changes within the monitoring period. We assume that the coherence of these points will lower with the use of more images in future.

The Ervěnice corridor is imaged in the middle of figure 5. It is a four-lane road, railway and pipelined river built in 1980s on a
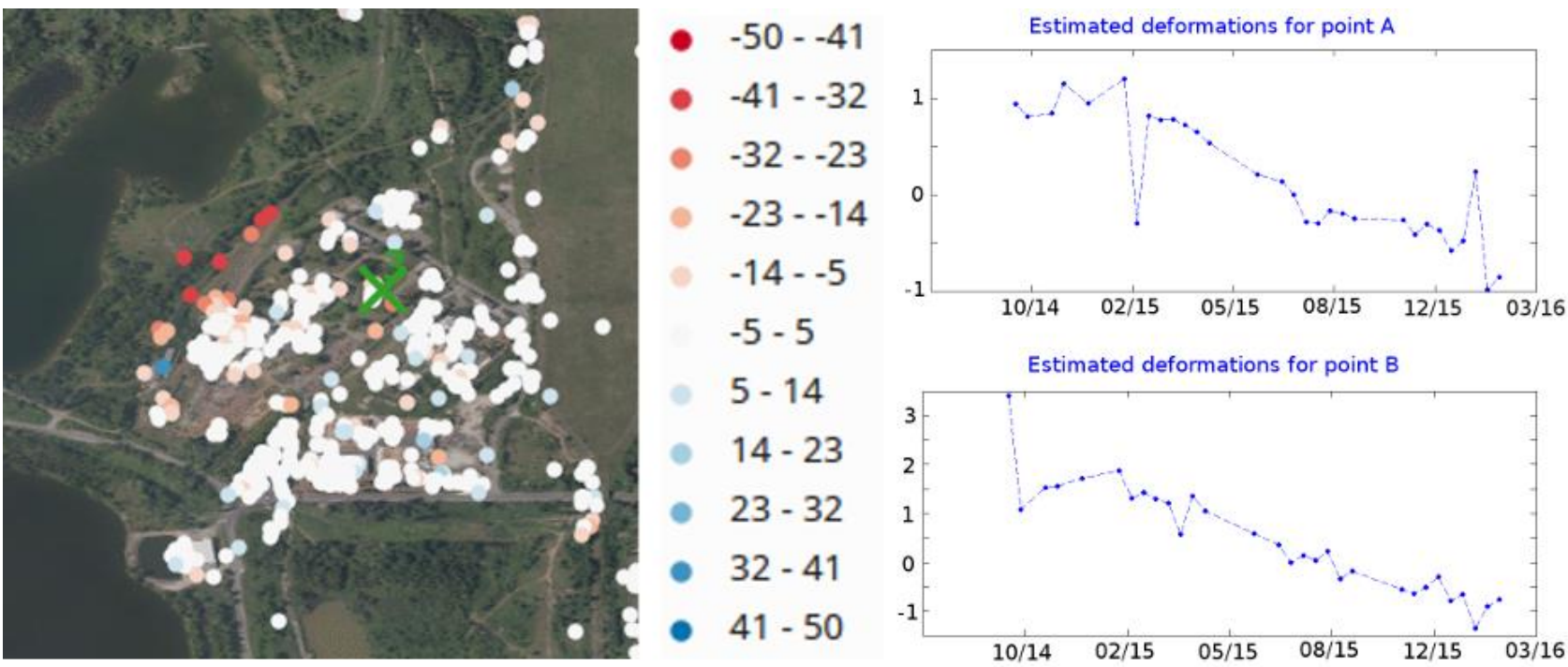

Figure 6. Sentinel-1 estimated movements (in LOS) for the area close to reflector 3 (Centrum mine). The area with marked with red dots is undermined (the mine is still active). The estimated deformations reach up to $25 \mathrm{~mm} / \mathrm{year}$ in LOS, corresponding to $32 \mathrm{~mm} /$ year in the vertical direction. The movements are estimated with regard to reflector 1 . The green cross corresponds to the position of reflector no. 3 . 
waste dump to provide the transport between the mining area and the cities around it. Its height is $170 \mathrm{~m}$ at maximum. In the first years after the construction, the subsidence in this area was in the order of $0.5 \mathrm{~m} / \mathrm{year}$ and the railway had to be reconstructed many times (Wikipedia, 2015). The railway is of the highest reflectivity, therefore the selected points (in Fig. 5) are mostly situated on it.

Now, it is visible that maximum subsidence at the corridor reaches about $4 \mathrm{~cm} /$ year.

Figure 6 depicts area close to reflector 3. The area is undermined, with subsidence velocities of around $2-3 \mathrm{~cm} /$ year (reflector 3 is situated out of the undermined area, and therefore is assumed to be stable (estimated deformations are in accord).

\section{CONCLUSIONS}

The first monitoring results with the Sentinel-1 data show that the corner reflectors are still visible in the images (even if the resolution is significantly worse in comparison to TerraSAR-X stripmap data), and that they are visible even if not re-oriented (this is the case of our area with the difference in the incidence angle of $8^{\circ}$, can be different with regard to the change in the incidence angle and the size of the reflectors).

However, the processing of Sentinel-1 data requires several steps which have not been necessary for InSAR processing images from older satellites, and if not properly coregistered, phase jumps arise in the interferograms that are not visible if only point processing is performed. One must therefore pay attention to them and if necessary, process each burst individually.

The advantage of the Sentinel-1 satellite is obviously the fact that data can be downloaded for free, with no previous order, and that the data were acquired for more than $70 \%$ of the passes, i.e. resulting in short temporal baselines. It is expected that the period between the subsequent acquisitions will be even shorter after the launch of Sentinel-1B satellite. And moreover, also the spatial baselines are very short in comparison to previous C-band satellites, also bringing more usable data pairs. A movement was detected at the bottom of the slope which appears to be an uplift due to the negative sensitivity of the expected movement direction with regard to the satellite line of sight. The movement can be probably attributed to hydrogeological changes and it seems to settle down after the autumn 2015.

\section{ACKNOWLEDGEMENTS}

The processing was performed in the SarPROZ@ software. For the processing, Sentinel-1A data were used, together with Xband SRTM DEM (provided by DLR) and ASTER DEM at the area where X-band SRTM DEM contains a hole (provided by NASA). The processing was performed in cooperation with Severní energetická, a.s.

\section{REFERENCES}

Barboux, C., et al., 2011. TSX InSAR Assessment for slope instabilities monitoring in alpine periglacial environment, presentation at FRINGE 2011.

Halounová, L. et al, 2013. Semi-automatic Processing of InSAR Data from Artificial Reflectors, TerraSAR-X Science Team Meeting.

Hlaváčová, I. et al, 2012. TerraSAR-X InSAR Processing in Northern Bohemia Coal Basin Using Corner Reflectors (Preliminary Results), ISPRS Annals of the Photogrammetry,
Remote Sensing and Spatial Information Sciences, Volume I-7, pp. $35-40$.

Hlaváčová, I. et al, 2014. The results of deformation monitoring in the Northern Bohemia using InSAR, Geodetický a kartografický obzor, 11/2014, pp. 291-300 (in Czech).

Ketelaar, V. B. H., 2008. Satellite Radar Interferometry: Subsidence Monitoring Techniques, Springer Science.

Prats-Iraola, P. et al, 2015. Investigations with the Sentinel-1 Interferometric Wide Swath Mode, presentation at FRINGE 2015.

Wikipedia, 2015. The Ervěnice corridor, https://cs.wikipedia.org/wiki/Erv\%C4\%9Bnick\%C3\%BD korid or (in Czech). 